\title{
Drug injection and associated factors among the elderly living with HIV/AIDS in Tehran, Iran
}

\author{
Salah Eddin Karimi ${ }^{1}$, Nasibeh Zanjari ${ }^{2}$, Neda SoleimanvandiAzar ${ }^{3}$, Elaheh Ahounbar ${ }^{4}$, Mohammad Ali Mohammadi \\ Gharehghani ${ }^{5}$, Sina Ahmadi ${ }^{5,6 *}$ (D)
}

Received: 26 Apr 2020

Published: 28 Apr 2021

\section{Abstract}

Background: Injection of drugs is one of the most serious health problems among Iranian living with HIV/AIDS. The injection of drugs, accounting for the transmission of more than two-thirds of HIV infections. HIV remains a major concern around the world and is expected to be the third leading cause of mortality worldwide. Thus, the aim of this study was to explore the predictors of injection drug use in the elderly patients living with HIV/AIDS.

Methods: This was a cross-sectional study executed in Tehran City, Iran, in 2018. A total of 160 individuals aged 60 years and older with HIV from different counseling centers were selected by convenience sampling. Data were collected using questionnaires including a positive state of mind, coping, social support, and a checklist of demographical variables. Bivariate analysis and multiple logistic regression using SPSS software version 21.0 were employed to determine factors associated with drug injection. The statistical tests were performed with a significance level of $5 \%(\mathrm{p} \geq 0.05)$.

Results: The study participants' mean(SD) age was $65.6( \pm 6.6)$ years. In total, 33 people $(20.6 \%)$ of the samples reported injection drug use. The frequency of injection drug use was greater among men (AOR: 2.28, 95\% CI 2.2-22.8; $\mathrm{p}=0.010$ ), those reporting a monthly income of $\geq 30000000$ Rials (AOR: $31.56,95 \%$ CI 2.95-338; $\mathrm{p}=0.004$ ), subjects with past experience of drug use (AOR: 7.11, 95\% CI 2.18-23.2; $\mathrm{p}=0.001$ ), those with $\geq 2$ years past from their HIV diagnosis (AOR: 4.04, 95\% CI 1.12-14.58; $\mathrm{p}=0.033$ ), and those living with more than two people in one residential place (Household size AOR: 5.9, 95\% CI 1.64-21.24; $\mathrm{p}=0.007$ ).

Conclusion: It seems that the design and implementation of harm reduction programs among the elderly with HIV/AIDS who inject drugs are essential and should be considered as an agenda of policymakers and health professionals.

Keywords: Drug Injection, Elderly People, HIV/AIDS, Drug Use, Determinants

Conflicts of Interest: None declared

Funding: This research was supported by grant No 13001 from Iran University of Medical Sciences

*This work has been published under CC BY-NC-SA 1.0 license.

Copyright $\odot$ Iran University of Medical Sciences

Cite this article as: Karimi SE, Zanjari N, SoleimanvandiAzar N, Ahounbar E, Mohammadi Gharehghani MA, Ahmadi S. Drug injection and associated factors among the elderly living with HIV/AIDS in Tehran, Iran. Med J Islam Repub Iran. 2021 (28 Apr);35:55. https://doi.org/10.47176/mjiri.35.55

\section{Introduction}

In spite of remarkable progress in the treatment of diseases over the prior decade, HIV remains a major concern around the world and is expected to be the third leading cause of mortality worldwide by 2030 (1). Pursuant to

Corresponding author:Dr Sina Ahmadi, Si.ahmadi25@uswr.ac.ir

1. Social Determinants of Health Research Center, Health Management and Safety Promotion Research Institute, Tabriz University of Medical Sciences, Tabriz, Iran

2. Iranian Research Centre on Aging, University of Social Welfare and Rehabilitation Sciences, Tehran, Iran

3. Preventive Medicine and Public Health Research Center, Psychosocial Health Research Institute, Iran University of Medical Sciences, Tehran, Iran

4. Substance Abuse and Dependence Research Center, University of Social Welfare and Rehabilitation Sciences, Tehran, Iran

5. Social Welfare Management Research Center, University of Social Welfare and Rehabilitation Sciences, Tehran, Iran

6. Department of Social Welfare Management, University of Social Welfare and Rehabilitation Sciences, Tehran, Iran global statistics, in 2015, 36.7 million individuals worldwide were infected with HIV (2). Even though the epidemiological evidence in recent years has been indicative of a decline in HIV infection in many developed coun-

$\uparrow$ What is "already known" in this topic:

In our study, the prevalence of drug injection and associated factors among the elderly living with HIV/AIDS in Tehran, Iran were studied.

\section{$\rightarrow$ What this article adds:}

This study showed the frequency of drug injection in the elderly living with HIV/AIDS was greater among men, those reporting a monthly income of 30000000 Rials, subjects with past experience of drug use, those with $\geq 2$ years past from their HIV diagnosis, and those living with more than two people in one residential place. 
tries, the prevalence of HIV is increasing in developing countries (3).

Substance abuse, which is prevalent in HIV patients (4) is among the infection transmission factors to others (5). According to the international reports, 25 million people suffer from substance dependence; of whom approximately 16 million (11-21 million) people inject drugs in the world, with about 3 million people (one to seven million) suffering from HIV/AIDS (6). The prevalence of HIV and hepatitis $\mathrm{C}$ virus infection were $13.5 \%$ and $52 \%$, respectively, in injection drug users in 2013. Drug injection is the most critical risk factor for blood-borne infections. Overall, $90 \%$ of injection drug users become affected with hepatitis $\mathrm{C}$ virus after 5 years of drug injection (7).

According to studies, there are approximately 1200000 to 2 million substance users $(8,9)$ and about 170000 to 224000 injection drug users $(9,10)$ in Iran; of whom $15 \%$ suffered from HIV (11). In recent years, injection drug use has been rising faster than non-injection practice and increased by about $30 \%$ annually. In addition, the development of two-thirds of new cases of HIV has been reported infected due to the injection of substances (12). Approximately $68 \%$ of Iran's HIV prevalence belonged to people who inject drugs (13). And about $2.8 \%$ of injection drug users are infected with HIV (14).

Injection drug use negatively affects social norms, increases crime, violence (15), increases the risk of bloodborne infections such as HIV, HCV, HBV, substance dependence (16-18), poisoning and death, committing suicide, substance smuggling, and rubbery (19). The UNAIDS Global Strategy for 2016-2021 to reach zero-point HIV focuses on the key high-risk populations, such as drug injectors, and the provision of effective interventions to them (20).

It is estimated that $10 \%$ of 37 million individuals with HIV worldwide are over 50 years and this trend is on the rise $(21,22)$. In the USA, $50 \%$ of individuals with HIV are over 50 years old and $11 \%$ are above 60 years old (1, 22). In general, one-fifth of diagnosed HIV cases are currently observed in people over 50 years of age (23). HIV and aging are correlated with extensive comorbidities, which require a wide range of treatment. There is no accurate data available on the frequency of HIV-positive elderly in Iran; however, with the onset of the transition from the middle-age period and the beginning of old ages in the near future, as well as the increased life expectancy in Iran, drug injection and HIV in older adults are among major concerns of the health sector.

Various studies have identified the associated risk factors for the initiation of drug injection (24). Some of the risk factors include the low cost of drug injection with the higher expected impact of substances $(25,26)$. Furthermore, other drug injection-related risk factors consist of homelessness, low economic status, male gender, involvement in sex work, and race (27-30). Overall, Risk factors for the initiation of injection drug use are classified at three individuals, familial, and social levels. These factors include unemployment, poverty, homelessness, exposure to violence, unsafe sexual contacts, discontinued education, early onset of substance use, environmental and social contexts (e.g., peer pressure and interactions with other injection drug users) (11, 31-34).

However, accurate investigations on the frequency of injection of substances among the elderly with HIV and its related factors have been overlooked. The provision of scientific evidence in this field of study could provide policymakers and health planners with the appropriate choices of health policies to optimally allocate resources, plan for preventive interventions, and promote community health (35). Thus, the present study aimed to investigate the predictors of injection drug use in older adults living with HIV/AIDS.

\section{Methods}

We conducted a cross-sectional survey of HIV-positive people aged $\geq 60$ years and older in June and October of 2018 in Teheran. Individuals were recruited using a convenience strategy at counseling centers and using participants to refer their peers to participate in the study. The inclusion criteria were the age of $\geq 60$ years, living with HIV/AIDS, residing in Tehran City for at least one month, communicating in Persian, and were able to provide informed consent to complete the interview.

Initially, a list of behavioral counseling centers affiliated to the medical universities of Tehran city was prepared, and four centers were selected from each university by chance. After getting the related permission to collect data, we referred to these centers for data collection and participants selected by convenience sampling method in the first step. They completed the anonymous self-report questionnaires after providing informed acquiescence to take part in the study and introduce their peers to participate in the study.

The applied questionnaire comprised 3 main sections, probing the following aspects: 1. socioeconomic characteristics (age, gender, marital status, birth location, educational degree, employment status, income level) and HIVrelated features (HIV/AIDS stages, drug use history, prison history, alcohol use); 2. The positive state of mind in the patient, social support, and coping with a standardized questionnaire; and 3. injection drug use. The former aspect was probed by a simple question: 'have you injected drugs in the past month?', with a yes/no answer.

The positive state of mind (PSOM) scale developed by Horowitz et al. (1988) was used. This scale evaluates the patient's positive mood and the individual's ability to achieve positive cognition. PSOM includes six questions to assess focused attention, productivity, responsible caretaking, restful repose, sensuous pleasure and sharing (36). The scale was translated to Persian regarding WHO protocol steps and the content and face validity were examined by 10 experts in gerontology and sociology field. The reliability coefficient of the scale was $\alpha=0.91$.

Social support was assessed using the Medical Outcomes Study-Social Support Scale (MOS-SSS). The MOS-SSS was developed by Sherbourne and Stewart in 1991. This scale measures the level of social support perceived by the patient by 19 items in a 5-point Likert scale. This scale covers both emotional and instrumental dimensions of social support (37). The validity and reliability of 
this questionnaire have been confirmed in the Persian language (38). The reliability coefficient of the scale was $\alpha=0.98$.

Coping was measured with a 25 items Brief-COPE in 4 dimensions and a 5-point Likert scale. Dimensions including seeking support with 8 items, acceptance with 5 items, disengagement / avoidance / escape with 9 items, and direct action with 3 items. The participants were asked to represent how often they used a particular strategy in the previous three months (39). The reliability coefficient of the scale was $\alpha=0.75$.

The Research Ethics Committee of the Iran University of Medical Sciences approved the study protocol and procedure. To analyze the achieved data, we applied descriptive and inferential statistics using SPSS.21.0. First, the bivariate analysis, such as chi-squared test, unpaired t-test conducted to examine the association between factors related to drug injection. Then, the independently associated risk factors for the injection or non-injection drug use were identified by multiple logistic regression analysis. "injection drug use " was demonstrated as a dichotomous variable. Regarding univariate analysis results, the variables were inserted in a logistic regression model to estimate the related adjusted effect. The univariate and regression logistic tests were performed on a significance level of $5 \%(\mathrm{p} \geq 0.05)$.

\section{Results}

In total, 160 individuals of both genders aged $\geq 60$ years suffering from HIV/AIDS were included in the present study. The information obtained from the questionnaire was reported in Table 1 . The study participants' mean $\pm \mathrm{SD}$ age was $65.6 \pm 6.6$ years. Most study participants were male $(65.6 \%)$, married $(60 \%)$, reported no academic-level education $(84.4 \%)$. In addition, $65.6 \%$ of the subjects reported alcohol consumption, and $23 \%$ reported substance use in the past month. Moreover, a history of being imprisoned $(25 \%)$ and a monthly income of Rials 15000000 $30000000(50.6 \%)$ were reported by them. Table 1 also lists using drug injection in the studied groups. In total, $20.6 \%$ of the samples reported injection drug use (CI95\%: $14.2 \%, 26.9 \%$ ).

The characteristics of the elderly with/without injection drug use reports were compared with each other. The male gender was dominant in the samples reporting no injection drug use $(97 \%, p=0.001)$. In addition, on the basis of the final multivariable regression model, the age of $\geq 69$ years (54\% vs. 27\% 66-69 y and 18\%: 60-65 y; p=0.010), being unemployed ( $23 \%$ vs. $1 \%$ employed; $\mathrm{p}=0.001)$, a low monthly income level $(48.1 \%$ vs. $3 \%$ average income; $\mathrm{p}=0.001)$, a high socioeconomic level $(84.4 \%$ vs. $15.6 \%$; $\mathrm{p}=0.001)$, past experience of drug use $(69.7 \%$ vs. $30.3 \%$;

\begin{tabular}{|c|c|c|c|c|}
\hline \multirow[t]{3}{*}{ Characteristic } & & \multicolumn{2}{|c|}{ Injecting drug use } & \multirow[t]{3}{*}{$\bar{p}$} \\
\hline & & \multirow{2}{*}{$\begin{array}{c}\mathrm{No}=127(79.4) \\
\text { No. }(\%)\end{array}$} & \multirow{2}{*}{$\begin{array}{c}\text { Yes }=33(20.6) \\
\text { No. }(\%)\end{array}$} & \\
\hline & & & & \\
\hline \multirow[t]{2}{*}{ Gender } & Male & $73(57.5)$ & $32(97)$ & 0.001 \\
\hline & Female & $54(42.5)$ & $1(3)$ & \\
\hline \multirow[t]{2}{*}{ Birth location } & Urban & $118(92.9)$ & $28(84.8)$ & 0.160 \\
\hline & Rural & $9(7.1)$ & $5(15.2)$ & \\
\hline \multirow[t]{3}{*}{ Age group } & $60-65$ & $70(55.1)$ & $6(18.2)$ & 0.010 \\
\hline & $66-69$ & $19(15)$ & $9(27.3)$ & \\
\hline & $\geq 70$ & $38(29.9)$ & $18(54.5)$ & \\
\hline \multirow[t]{3}{*}{ Marital status } & Single & $10(7.9)$ & $2(6.1)$ & 0.610 \\
\hline & Married & $74(58.3)$ & $22(66.7)$ & \\
\hline & Separated & $43(33.9)$ & $9(27.3)$ & \\
\hline \multirow[t]{2}{*}{ Educational level } & Illiterate & $103(81.1)$ & $32(97)$ & 0.500 \\
\hline & Literate & $24(18.9)$ & $1(3)$ & \\
\hline \multirow{4}{*}{ Employment status } & Housewives & $37(29.1)$ & $2(6.1)$ & 0.001 \\
\hline & Employed & $22(17.3)$ & $1(3)$ & \\
\hline & Retired & $32(25.2)$ & $7(21.2)$ & \\
\hline & Unemployed & $36(28.3)$ & $23(69.7)$ & \\
\hline \multirow[t]{3}{*}{ Income level (Rials) } & $<15000000$ & $21(16.5)$ & $16(48.5)$ & 0.001 \\
\hline & $15000000-30000000$ & $41(32.3)$ & $1(3)$ & \\
\hline & $>30000000$ & $65(51.2)$ & $16(48.5)$ & \\
\hline \multirow[t]{3}{*}{ Socioeconomic level } & Low & $5(3.9)$ & $1(3)$ & 0.001 \\
\hline & Median & $60(47.2)$ & $4(12.1)$ & \\
\hline & High & $62(48.8)$ & $28(84.8)$ & \\
\hline \multirow[t]{2}{*}{ Infection time } & $<2$ years & $62(48.8)$ & $27(81.8)$ & 0.001 \\
\hline & $\geq 2$ years & $65(51.2)$ & $6(18.2)$ & \\
\hline \multirow[t]{2}{*}{ Imprison experience } & Yes & $19(15)$ & $21(63.6)$ & 0.001 \\
\hline & No & $108(85)$ & $12(36.4)$ & \\
\hline \multirow[t]{2}{*}{ Alcohol consumption } & Yes & $73(57.5)$ & $29(87.9)$ & 0.001 \\
\hline & No & $54(42.5)$ & $4(12.1)$ & \\
\hline Positive state of mind & $($ mean $\pm \mathrm{SD})$ & $(2.1 \pm 71)$ & $(2.4 \pm .57)$ & 0.014 \\
\hline Social support & $($ mean $\pm \mathrm{SD})$ & $(3.4 \pm 1.3)$ & $(3.1 \pm . .93)$ & 0.024 \\
\hline Coping & $($ mean $\pm \mathrm{SD})$ & $(3.5 \pm .43)$ & $(3.4 \pm .35)$ & 0.056 \\
\hline \multirow[t]{2}{*}{ Household size } & $<2$ & $77(60.6)$ & $17(51.5)$ & 0.200 \\
\hline & $\geq 2$ & $50(39.4)$ & $16(48.5)$ & \\
\hline \multirow[t]{2}{*}{ Drug use history } & No & $113(89)$ & $10(30.3)$ & 0.001 \\
\hline & Yes & $14(11)$ & $23(69.7)$ & \\
\hline
\end{tabular}




\begin{tabular}{|c|c|c|c|c|c|}
\hline \multirow[t]{2}{*}{ Characteristics } & & \multirow[t]{2}{*}{ AOR } & \multicolumn{2}{|c|}{$95 \% \mathrm{CI}$} & \multirow[t]{2}{*}{$\bar{p}$} \\
\hline & & & Lower & Upper & \\
\hline \multirow[t]{2}{*}{ Gender } & Male & 2.28 & 2.28 & 22.85 & 0.008 \\
\hline & Female & 1 & & & \\
\hline \multirow[t]{3}{*}{ Income level (Rials) } & $<15000000$ & 1 & & & \\
\hline & $15000000-30000000$ & 6.96 & .73 & 65.87 & \\
\hline & $>30000000$ & 31.65 & 2.95 & 338.97 & 0.004 \\
\hline \multirow[t]{2}{*}{ Drug use in the past } & Yes & 7.11 & 2.18 & 23.20 & 0.001 \\
\hline & No & 1 & & & \\
\hline \multirow[t]{2}{*}{ Infection time } & $<2$ years & 1 & & & \\
\hline & $>2$ years & 4.04 & 1.12 & 14.58 & 0.033 \\
\hline \multirow[t]{2}{*}{ Household size } & $<2$ & 1 & & & \\
\hline & $>2$ & 5.90 & 1.6 & 21.2 & 0.007 \\
\hline
\end{tabular}

$\mathrm{p}=0.001)$, having an experience of imprison $(63.6 \%$ vs. $36.4 \% ; \mathrm{p}=0.001)$, and the consumption of alcohol $(87.9 \%$ vs. $12.1 \% ; p=0.001)$ were determinants of injection drug use (Table 1).

The frequency of injection drug consumption was greater among men (AOR: 2.28, 95\% CI 2.2-228; $\mathrm{p}=0.008$ ), those reporting a monthly income of more than 15000000 Rials (AOR: $31.56,95 \%$ CI 2.95,338; $\mathrm{p}=0.0004$ ), subjects with past experience of drug use (AOR: 7.11, 95\% CI $2.18,23.2 ; \mathrm{p}=0.001)$, those with $\geq 2$ years past from their HIV diagnosis (AOR: 4.04, 95\% CI 1.12,14.58; $\mathrm{P}=0.033$ ), and those living with more than two people in one residential place (Household size AOR: 5.9, 95\% CI 1.64,21.24; $\mathrm{p}=0.007$ ) (Table 2).

\section{Discussion}

The current study examined the factors associated with drug injection in the elderly living with HIV. To the best of our knowledge, this is the first study to examine the factors related to injecting drugs in the elderly. Our findings suggested that one-fifth of the elderly living with HIV/AIDS Injecting drug use. The obtained data revealed that males, individuals who earn less than 15000000 Rials per month, those with no past experience of drug abuse, people with less than a two-year history of HIV/AIDS incidence, and the individuals living with fewer than two people in one residential place demonstrate less tendency toward injection drug use.

The high prevalence rate of drug injection in the HIVpositive elderly is consistent with previous studies conducted in Iran that reported high rates of drug injection in people with HIV $(14,40)$. However, a study in Spain indicated that only $3.6 \%$ of HIV infected people inject drugs (41). Other study findings suggested that some of the sociodemographic variables are associated with injecting drugs in the HIV-positive elderly $(14,40)$.

Research studies suggested that injection drug use is significantly higher among HIV-infected males; this finding is consistent with other studies (42) as well as results of national surveys. From 208000 injectors in Iran, 193000 were males, and only 16000 of them were females (43). Also, due to Iran's cultural-religious context, Iranian women are less likely to abuse drugs and inject drugs accordingly.

The achieved results suggested a correlation between income and the injection of substances; those who earned more than 15000000 Rials per month reported significant- ly more rates of drug injections. These findings are consistent with the study by Neupane, Mishra, Adhikari, Poudyal in 2014 (44), but contrary to a previous study in Iran (45). The former research concluded that drug injection is more prevalent among people from lower socioeconomic status. They also suggested that the practice of drug injection may lead to reduced financial resources after a while.

According to the obtained data, more years living with HIV infection would be correlated with the higher risk of drug injections among older adults. Drug injection appears to be a method of coping with the disease or reducing pain in patients with HIV/AIDS. In addition, it seems living longer with HIV/AIDS results in more engaging risky behaviors.

We also found a significant relationship between drug use in the past and drug injection in the past month. This finding suggests that we should focus on reducing drug abuse among people with HIV. This could be explained by the point that substance abusers fail to find the desired relief after a while and seek drug injection. In addition, those with a history of drug abuse recognize drug injection as a more common practice than others.

Eventually, the present study revealed that the odds of drug injection enhances with an increase in the number of people sharing the same living residence. In contrast to our study, another investigation argued that drug injection is more prevalent in the household with fewer members (46).

This data should be generalized with caution. Because it seems that with the increase in the number of positive social network members of the patient, risky behaviors are probably reduced; however, the findings are in contrast to such an assumption. One possible reason for this may be that these people are likely to live in shelters or are homeless, or are under the pressure of the people who live with them to inject drugs; thus, further research is required in this area. Based on our results, it seems that proper and relevant interventions should be designed and managed to reduce drug consumption among HIV-positive people, and also appropriate support should be provided to improve the socioeconomic situation of elderly people.

The present study was associated with several limitations. This observational study could only report factors related to drug injection in elderly individuals living with HIV/AIDS. In addition, obtaining data was based on selfreports provided by the subjects; thus, those may be ex- 
posed to recall or social bias. There might have been some errors in categorizing the injection drug users according to the mentioned characteristics. Also, conducting a random sampling method was not possible in this study; therefore, the data generalizability should be done with caution.

\section{Conclusion}

As the population of elderly living with HIV/AIDS continues to increase, policies will need to address a broad range of issues. For older adults with HIV, especially those who have been or are currently injecting drug, health care management must go beyond a focus on viral suppression. It seems that the design and implementation of harm reduction programs among the elderly with HIV/AIDS who inject drugs is essential and should be considered as an agenda of policymakers and health professionals

\section{Acknowledgments}

This research was supported by grant no. 97-3-62-13001 and the ethics code of IR.IUMS.REC.1397.478 from Iran University of Medical sciences.

\section{Conflict of Interests}

The authors declare that they have no competing interests.

\section{References}

1.Puhr R, Kumarasamy N, Ly PS, Ng OT, Van Nguyen K, Merati TP, et al. HIV and aging: Demographic change in the Asia-Pacific region. J Acquir Immune Defic Syndr. 2017;74(5):e146.

2.Karimi SE, SoleimanvandiAzar N, Zanjari N, Ahmadi S, Mohammadi Gharehghani MA, Faez D. Social determinants of drug use among older people with HIV/AIDS in Tehran. J Subst Use. 2020;25(6):610-614.

3. Baral S, Beyrer C, Muessig K, Poteat T, Wirtz AL, Decker MR, et al. Burden of HIV among female sex workers in low-income and middleincome countries: a systematic review and meta-analysis. Lancet Infect Dis. 2012;12(7):538-49.

4. Noroozi M, Rahimi E, Ghisvand H, Qorbani M, Sharifi H, Noroozi A, et al. Decomposition of economic inequality in needle and syringe programs utilization to its determinants among men who inject drugs in tehran using blinder-oaxaca decomposition method. Subst Use Misuse. 2018;53(7):1170-1176.

5. MacArthur GJ, Minozzi S, Martin N, Vickerman P, Deren S, Bruneau $\mathrm{J}$, et al. Opiate substitution treatment and HIV transmission in people who inject drugs: systematic review and meta-analysis. $\mathrm{Br}$ Med J. 2012;345.

6. Noroozi M, Rahimi E, Ghisvand H, Qorbani M, Sharifi H, Noroozi A, et al. Decomposition of economic inequality in needle and syringe programs utilization to its determinants among men who inject drugs in tehran using blinder-oaxaca decomposition method. Subst Use Misuse. 2018;53(7):1170-6

7. Noroozi M, Ahounbar E, Karimi SE, Ahmadi S, Najafi M, Bazrafshan $\mathrm{A}$, et al. HIV risk perception and risky behavior among people who inject drugs in Kermanshah, Western Iran. Int J Behav Dev. 2017;24(4):613-8.

8. INCB. The report of the International Narcotics Control Board for 2009 New York: UNITED NATIONS; 2009 [Available from: https://www.incb.org/incb/en/publications/annual-reports/annualreport-2009.html.

9. Karimi SE, Bayani A, Higgs P, Bayat AH, Hemmat M, Ahounbar E, et al. Prevalence and high risk behaviours associated with HCV testing among people who inject drugs: a systematic review and Metaanalysis. Subst Abuse Treat Prev Policy. 2020;15(1):1-16.

10. Sharhani A, Shushtari ZJ, Rahmani A, Armoon B, Noroozi M, Ahounbar E, et al. Incidence of HIV and HCV in people who inject drugs: a systematic and meta-analysis review protocol. BMJ Open. 2021;11(1):e041482.

11. Noroozi M, Ahmadi S, Armoon B, Jorjoran Shushtari Z, Sharhani A, Ahounbar E, et al. Social determinants associated with risky sexual behaviors among men who inject drugs in Kermanshah, Western Iran. J Subst Use. 2018;23(6):591-596.

12. Rahimi-Movaghar A, Amin-Esmaeili M, Shadloo B, Noroozi A, Malekinejad M. Transition to injecting drug use in Iran: A systematic review of qualitative and quantitative evidence Int J Drug Policy 2015;26(9):808-19.

13. Zamani S, Kihara M, Gouya MM, Vazirian M, Ono-Kihara M, Razzaghi EM, et al. Prevalence of and factors associated with HIV-1 infection among drug users visiting treatment centers in Tehran, Iran. Aids. 2005;19(7):709-16.

14. Khajehkazemi R, Osooli M, Sajadi L, Karamouzian M, Sedaghat A, Fahimfar N, et al. HIV prevalence and risk behaviours among people who inject drugs in Iran: the 2010 National Surveillance Survey. Sex Transm Infect. 2013;89(Suppl 3):29-32.

15. Rafiei H, Madani-GHahfarokhi S, Vameghi M. Priorities of Social Problems in Iran. ISA. 2008;9(1,2):151-60.

16. Garfein RS, Vlahov D, Galai N, Doherty MC, Nelson KE. Viral infections in short-term injection drug users: the prevalence of the hepatitis $\mathrm{C}$, hepatitis B, human immunodeficiency, and human Tlymphotropic viruses. Am J Public Health. 1996;86(5):655-61.

17. Gossop M, Griffiths P, Powis B, Strang J. Cocaine: patterns of use, route of administration, and severity of dependence. Br J Psychiatry. 1994;164(5):660-4.

18. Xia X, Luo J, Bai J, Yu R. Epidemiology of hepatitis $\mathrm{C}$ virus infection among injection drug users in China: Systematic review and meta-analysis. Public Health. 2008;122(10):990-1003.

19. CDC. Recommendations for prevention and control of hepatitis $C$ virus $(\mathrm{HCV})$ infection and $\mathrm{HCV}$-related chronic disease. Centers for Disease Control and Prevention; 1998 Oct 16. Report No.: 1057-5987 (Print) 1057-5987 Contract No.: Rr-19.

20. UNODC. World drug report 2015. New York: United Nations Office on Drugs and Crime; 2015.

21. Millar BM, Starks TJ, Gurung S, Parsons JT. The impact of comorbidities, depression, and substance use problems on quality of life among older adults living with HIV. AIDS Behav. 2017;21(6):1684-90.

22. Wing EJ. HIV and aging J Infect Dis. 2016;53:61-8.

23. Blaylock JM, Wortmann GW. Care of the aging HIV patient. Clevel Clin J Med. 2015;82(7):445-55

24. Mathers BM, Degenhardt L, Bucello C, Lemon J, Wiessing L, Hickman M. Mortality among people who inject drugs: a systematic review and meta-analysis. Bull World Health Organ. 2013;91(2):10223.

25. Goldsamt LA, Harocopos A, Kobrak P, Jost JJ, Clatts MC. Circumstances, pedagogy and rationales for injection initiation among new drug injectors. J Commun Health. 2010;35(3):258-67.

26. Witteveen E, Van Ameijden EJ, Schippers GM. Motives for and against injecting drug use among young adults in Amsterdam: qualitative findings and considerations for disease prevention. Subst Use Misuse. 2006;41(6-7):1001-16.

27. Noroozi M, Farhadi MH, Armoon B, Farhoudian A, Shushtari ZJ, Sharhani A, et al. Factors associated with time between using a drug and injection initiation among people who inject drugs in Kermanshah, Iran. Int J Adolesc Med Health. 2018;32(5).

28. Hadland SE, Werb D, Kerr T, Fu E, Wang H, Montaner JS, et al. Childhood sexual abuse and risk for initiating injection drug use: a prospective cohort study. Prev Med. 2012;55(5):500-4.

29. Miller CL, Pearce ME, Moniruzzaman A, Thomas V, Christian W, Schechter MT, et al. The Cedar Project: risk factors for transition to injection drug use among young, urban Aboriginal people. CMAJ. 2011;183(10):1147-54

30. Sharifi H, Mirzazadeh A, Noroozi A, Marshall BD, Farhoudian A, Higgs $\mathrm{P}$, et al. Patterns of HIV Risks and Related Factors among People Who Inject Drugs in Kermanshah, Iran: A Latent Class Analysis. J Psychoact Drugs. 2017;49(1):69-73.

31. Guichard A, Guignard R, Michels D, Beck F, Arwidson P, Lert F, et al. Changing patterns of first injection across key periods of the French Harm Reduction Policy: PrimInject, a cross sectional analysis. Drug Alcohol Depend. 2013;133(1):254-61.

32. Neaigus A, Miller M, Friedman SR, Hagen DL, Sifaneck SJ, Ildefonso $\mathrm{G}$, et al. Potential risk factors for the transition to injecting among non-injecting heroin users: a comparison of former injectors 
and never injectors. Addiction. 2001;96(6):847-60.

33. Rahimi-Movaghar A, Amin-Esmaeili M, Shadloo B, Noroozi A, Malekinejad M. Transition to injecting drug use in Iran: A systematic review of qualitative and quantitative evidence. Int J Drug Policy. 2015;26(9):808-19.

34. Malekinejad M, Vazirian, M. Transition to injection amongst opioid users in Iran: implications for harm reduction Int J Drug Policy. 2012;23(4):333-7.

35. Roy É, Haley N, Leclerc P, Cédras L, Blais L, Boivin J. Drug injection among street youths in Montreal: predictors of initiation. J Urban Health. 2003;80(1):92-105.

36. Horowitz M, Adler N, Kegeles S. A scale for measuring the occurrence of positive states of mind: a preliminary report. Psychosom Med. 1988;50(5):477-83.

37. Sherbourne CD, Stewart A.The MOS social support survey. Soc Sci Med. 1991;32(6):705-14.

38. Mohammadzadeh J, Sayehmiri K, Mahmoudi B. Standardization of Social Support Scale (MOS) of Adults who have Chronic Diseases in Ilam. J Ikam Univ Med Sci. 2016;23(7):69-77.

39. Faraji E, Sardashti S, Firouzeh MM, Aminabad FJ, Alinaghi SAS, Hajiabdolbaghi M. Perceived social support affects disease coping among people living with HIV: a study in Tehran, Iran. Asian Pacific J Trop Dis. 2015;5(5):412-7.

40. Alipour A, Haghdoost AA, Sajadi L, Zolala F. HIV prevalence and related risk behaviours among female partners of male injecting drugs users in Iran: results of a bio-behavioural survey, 2010. Sex Transm Infect. 2013;89(Suppl 3):41-4.

41. Fuster-RuizdeApodaca MJ, Castro-Granell V, Garin N, Laguía A, Jaén Á, Iniesta C, et al. Prevalence and patterns of illicit drug use in people living with HIV in Spain: A cross-sectional study. PLoS One. 2019;14(6): 0211252.

42. Bluthenthal RN, Wenger L, Chu D, Lorvick J, Quinn B, Thing JP, et al. Factors associated with being asked to initiate someone into injection drug use. Drug Alcohol Depend. 2015;149:252-8.

43. Shahesmaeili A, Haghdoost AA, Soori H. Network location and risk of human immunodeficiency virus transmission among injecting drug users: Results of multiple membership multilevel modeling of social networks. Addiction Health. 2015;7(1-2):1.

44. Neupane SR, Mishra SR, Adhikari S, Poudyal A. Socio-demographic correlates of injection drug use among male drug users: A cross sectional study in Nepal. J Commun Health. 2014;39(6):1124-32.

45. Koozegar M, Shahesmaeili A, Noroozi M. Transition from first drug use to regular injection among people who inject drugs in Iran. Addiction Health. 2018;10(1):32.

46. Ahmed T, Long TN, Huong PT, Stewart D. Drug injecting and HIV risk among injecting drug users in Hai Phong, Vietnam: a qualitative analysis. BMC Public Health. 2015;15(1):1-13. 